\title{
Pharmacology in undergraduate nursing education: I nnovative strategies for enhancing medication related knowledge, attitudes, skills and behaviours
}

\author{
Cynthia D. Barkhouse-MacKeen ${ }^{1}$, Andrea L. Murphy² \\ 1. School of Nursing, Dalhousie University, Halifax, Nova Scotia, Canada. 2. College of Pharmacy and Department of \\ Psychiatry, Dalhousie University, Halifax, Nova Scotia, Canada
}

Correspondence: Cynthia D. Barkhouse-MacKeen. Address: School of Nursing, 5869 University Avenue, P. O. Box 5000 Halifax, Nova Scotia, Canada B3H 4R2. Telephone: 01-902-494-2225. Email: cynthia.barkhouse.mackeen@dal.ca.

Received: August 1, 2012

DOI : $10.5430 /$ jnep.v3n6p91
Accepted: August 22, 2012

URL: http://dx.doi.org/10.5430/jnep.v3n6p91
Online Published: January 4, 2013

\begin{abstract}
Medications are commonly used interventions in healthcare. As our population ages and the prevalence of chronic health challenges increases, medication management has become increasingly complex. Although medication management is a collaborative team effort among health care providers, nurses have a major role in the clinical assessment and monitoring of patients. Nurses are also responsible for medication administration and related drug dosage calculations in the care of patients. There is a growing body of literature that highlights gaps in knowledge and applied skills of nursing students and practicing nurses in pharmacology content and drug dosage calculations.

Teaching pharmacology, drug dosage calculations, and medication administration techniques requires innovative strategies to promote student learning, achievement of outcomes, and life-long learning principles in undergraduate nursing education. We present evidence-informed, innovative strategies and techniques from classroom and Clinical Learning and Simulation Centre experiences that were employed in order to improve student learning and success in an undergraduate pharmacology course. The most notable of course outcomes is that of students' enhanced abilities to exercise clinical reasoning with regard to application of the medication related knowledge and skills.
\end{abstract}

\section{Key words}

Pharmacology, Drug dosage calculations, Nursing education

\section{Background}

Pharmacotherapeutics is a complex part of clinical care that requires collaboration of the prescriber, the pharmacy team, and nursing staff. Nurses play a critical role in medication management in various settings within our health care system. Performing this role in an effective, efficient and safe manner is challenging due to various system, patient, and nurse specific factors. To exemplify a patient factor, polypharmacy in older Canadians is common, with an estimated $62 \%$ of seniors with public drug plan coverage using 5 or more medications from different drug classes ${ }^{[1]}$. Further, our population is living longer with chronic illnesses, putting them at risk for potential exacerbations and complications that can lead to hospital admissions. Comprehensive assessment of these patients and their medication regimens is more complicated and 
necessary because of these factors and the significant direct and indirect costs to the system, patients, and society that medication related adverse events and error generate. From the system perspective, the work environment for nurses is complex. In hospital settings, a significant amount of time is spent in medication-related tasks and, while performing these tasks, nurses are frequently interrupted ${ }^{[2]}$. Some of the factors affecting safety in assessment, medication administration and monitoring are reflected in lack of experience, fatigue caused by shiftwork/overtime, and stress ${ }^{[3]}$. Brady et al. also outlined knowledge, medication reconciliation, mathematical skills, and deviation from procedures as some of the key factors contributing to errors by nurses ${ }^{[3]}$. Others have also developed unique approaches to determine nurses' interactions with their working environments in order to explore factors (e.g. ward climate and nursing insecurities) and how these variables contribute to nurses' errors ${ }^{[4]}$.

It is important for undergraduate curricula to prepare nursing graduates for entry to practice in a complex health care environment and also engage them regarding the practice of life-long learning. This preparation would include adequate content and practical experience regarding pharmacodynamics and kinetics, pharmacotherapeutic considerations, as well as effective, efficient and safe medication administration techniques and relevant dosage calculations. Additionally, the graduates would be prepared with practical skills that would facilitate maintaining competency and keeping up to date with medication information. Some research has demonstrated however that graduating nurses are limited in their pharmacology and calculation knowledge ${ }^{[5]}$.

Prior to 2002, the pharmacology course in the undergraduate nursing program at Dalhousie University in Halifax, Nova Scotia, Canada, was taught in sections with medication administration lectures delivered first by a nurse followed by pharmacology content delivered via didactic lectures by various pharmacology department faculty. This nurse was also responsible for the medication administration practical experiences in the laboratory setting. There was no dedicated arrangement for content to be overtly complementary or inclusive between the pharmacology and medication administration related components of the course, and this was reflected in student evaluations. The course was perceived by students to be difficult and had a dosage calculations failure rate of approximately $35 \%$. Students were taught dosage calculations in the classroom without formally linking evidence for best practice in teaching the calculation skills in recognition of different mathematical learning styles and background. The School of Nursing faculty recognized the need for more collaborative teaching strategies to mirror the clinical practice environment and to improve student success in the course. This approach would enable student integration of complex pharmacological concepts with practical application. In response to this need, a pharmacist (AM) with an accredited Canadian hospital pharmacy residency and a post-baccalaureate Doctor of Pharmacy degree was hired in 2002 as a faculty member in the School of Nursing at Dalhousie University. She assumed responsibility for the pharmacology content related to the course in the undergraduate program and pharmacotherapeutic content for nurse practitioners in the graduate program. This change represented an opportunity, led by the clinical nurse specialist faculty member (CBM) responsible for the course outcomes, for reorganization of the undergraduate pharmacology course with enhanced linkages among the medication administration lectures, practical experiences within the Clinical Learning and Simulation Centre (CLSC), and pharmacology content.

\section{Aim of the article}

We describe innovative strategies in an undergraduate pharmacology course with large class numbers (e.g. 130 to 180) to enhance nursing students' medication-related knowledge, attitudes, skills and behaviours in their preparation towards assuming their role in medication management.

\section{Activity descriptions}

\section{I ntegrated pharmacology and nursing content}

The pharmacology course occurs in the second year of the program and is typically delivered over thirteen weeks. Six, one-hour, medication administration lectures are spread out over the course's term with one per week during the first six weeks. Each medication administration lecture is scheduled prior to the students' weekly Clinical Learning and Simulation 
Centre (CLSC) experience. Clinical instructors, facilitators of the CLSC experiences, often attend the medication administration and the pharmacology lectures to enhance content continuity. The pharmacist attends the CLSC experiences to observe and participate for continuity purposes and to model interdisciplinary practice amongst nurses and pharmacists. The CLSC experiences are case-based and students are required to use a real world approach to the assessment of therapeutic interventions and medication administration. For example, unit dose packages containing inactive substances (e.g. breath mints) mimicking currently available, commonly used medications are administered by students to each other in week one of lab while conducting clinical assessments. A performance criteria list, based on medication administration standards (see Table 1), is available for students to conduct a self-assessment. Each week, a new performance criteria list is used depending on the route of administration. Performance criteria are in place for certain medications (e.g. insulin, heparin) where research evidence is used to highlight changes or differences when administration technique varies from standard procedures.

Table 1. N 2050.03 - Medication Administration Skills Assessment

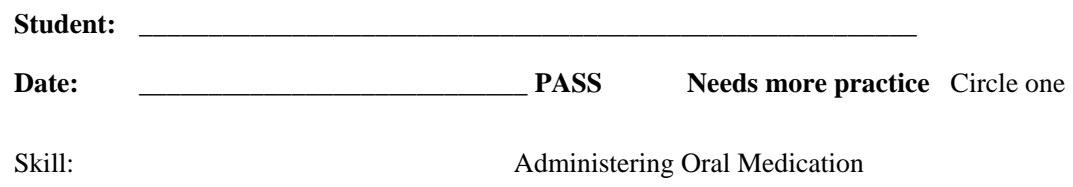

Successful Performance: The student will safely administer oral medications (simulation with partner peer in lab).

1) Criteria in shaded areas must be completed safely and accurately. Failure to demonstrate any one of these criteria will mean more practice is required. Students will successfully pass with up to six mistakes/missed criteria (other than those critical elements in the shaded areas).

2) Students may practice as many times as needed, Successful demonstration by each student is needed to proceed to the next lab. The practice group of students will provide an instructor with completed form (all student names on one form). The instructor will determine success by signing and keeping the form.

\begin{tabular}{|c|c|c|}
\hline Performance Criteria & Completed & Not completed \\
\hline \multicolumn{3}{|l|}{$\begin{array}{l}\text { 1. Maintains infection control principles - performs hand hygiene, uses aseptic technique (I.e. does } \\
\text { not handle medication, clean gloves if touching med). }\end{array}$} \\
\hline \multicolumn{3}{|l|}{ 2. Gathers appropriate equipment, uses clean working surface. } \\
\hline \multicolumn{3}{|l|}{ 3. Verifies dr's order with MAR, clarifies incomplete or illegible orders. Checks allergies. } \\
\hline \multicolumn{3}{|l|}{$\begin{array}{l}\text { 4. Using } 5 \text { of } 8 \text { "Rights of Administration" (verbalizes to instructor), accurately prepares medication } \\
\text { dosage \& double checks dosage calculations, demonstrating psychomotor skills for placing } \\
\text { medication in paper med cup. Demonstrates } 3 \text { checks of label with MAR, checks med expiry date. }\end{array}$} \\
\hline \multicolumn{3}{|l|}{ 5. Determines interaction with any meds, clarifies with physician prn. } \\
\hline \multicolumn{3}{|l|}{$\begin{array}{l}\text { 6. When preparing a liquid, pours from bottle with label facing nurse to avoid liquid wetting the } \\
\text { label. Pours medication in cup at eye level, with bottom of meniscus at the measure line on cup. Uses } \\
\text { syringe to prepare doses }<10 \mathrm{ml} \text { to ensure accuracy. }\end{array}$} \\
\hline \multicolumn{3}{|l|}{$\begin{array}{l}\text { 7. When splitting tablets, ensures tablet is scored or collaborates with pharmacist for liquid } \\
\text { preparation/alternate supply dose if possible. }\end{array}$} \\
\hline \multicolumn{3}{|l|}{$\begin{array}{l}\text { 8. Reviews appropriate lab data (e.g. checks potassium level if on diuretic) and assessment data (e. g. } \\
\text { vital sign trends, fluid restriction, dysphagia s\&s- drooling, "gargly voice”, weak/absent cough, } \\
\text { unable to hold head up) }\end{array}$} \\
\hline \multicolumn{3}{|l|}{$\begin{array}{l}\text { 9. If preparing a narcotic, counts narcotic med balance before and after removing medication from } \\
\text { narcotic cupboard. Documents on narcotic record. }\end{array}$} \\
\hline \multicolumn{3}{|l|}{ 10. Identifies client - checks armband. } \\
\hline \multicolumn{3}{|l|}{ 11. Checks with client to confirm allergy status. } \\
\hline Performance Criteria (cont) & Completed & Not completed \\
\hline \multicolumn{3}{|l|}{$\begin{array}{l}\text { 12. Explains procedure and medication indications (I.e why client is taking med). Assesses client’s } \\
\text { knowledge of medication(s), using appropriate language for client teaching.( } 6^{\text {th }} \text { Right: "to know") }\end{array}$} \\
\hline $\begin{array}{l}\text { 13. Assesses if meds can be swallowed safely, checks whether safe to crush, if crushing. Positions } \\
\text { client sitting to minimize risk for aspiration, using pillows for support/comfort, prn. }\end{array}$ & & \\
\hline
\end{tabular}

(Table 1 continued on page 94) 
Table 1. (continued)

\begin{tabular}{|c|c|}
\hline $\begin{array}{l}\text { 14. Considers client preference for fluids \& assesses compatibility with med (e.g. should/should not } \\
\text { be given with milk). }\end{array}$ & \\
\hline 15. Allows client to hold medication in hand or cup and fluid container as able. & \\
\hline $\begin{array}{l}\text { 16. Stays with client until medication is swallowed Encourages full glass ( } 240 \mathrm{ml} \text { ) of water/fluid if } \\
\text { able \& not fluid restricted, to minimize nausea and vomiting from high osmolarity (concentration) of } \\
\text { medication. }\end{array}$ & \\
\hline $\begin{array}{l}\text { 17. If tablet falls to floor, discards and repeats preparation procedure. Collaborates with pharmacist } \\
\text { to obtain replacement med. }\end{array}$ & \\
\hline $\begin{array}{l}\text { 18. Repositions client comfortably. Positions call bell within reach. (If client is in bed, puts bed down } \\
\text { to lowest height, raises side rails.) }\end{array}$ & \\
\hline 19. Discards supplies appropriately. & \\
\hline 20. Documents medication administration on MAR $-8^{\text {th }}$ Right; returns MAR to appropriate location. & \\
\hline $\begin{array}{l}\text { 21. Documents and reports/takes appropriate action if med is withheld or refused }-7^{\text {th }} \text { Right (e.g. if } \\
\text { pulse is below } 60 \text {, consider whether drug should be held; hold if below } 50-\text { collaborate with } \\
\text { physician for orders) }\end{array}$ & \\
\hline $\begin{array}{l}\text { 22. Evaluates client response to medication (particular attention to prn meds) in a timely manner and } \\
\text { documents response to prn meds. }\end{array}$ & \\
\hline $\begin{array}{l}\text { 23. Documents/reports adverse response to any med- collaborates with physician for orders (e.g. if } \\
\text { rash develops). }\end{array}$ & \\
\hline Instructor’s Signature: & $\begin{array}{l}\text { 14/14 critical } \\
\text { elements completed } \\
\text { Yes No } \\
\text { Total Score of other } \\
\text { elements=/23 }\end{array}$ \\
\hline
\end{tabular}

Pharmacology lectures are delivered twice weekly for the first six weeks and then three times weekly for the next seven weeks. The content is taught at a level that reflects entry to practice for nurses. The molecular and cellular basis of pharmacodynamics and kinetics are used to inform the lecture content but the emphasis is placed on clinical application of the concepts. The pharmacology lectures reference the case studies from the CLSC to demonstrate clinical application of pharmacology principles. Critical thinking is encouraged through application of various concepts. Within the lectures designated to contain pharmacology-related content, there are two lectures that specifically address searching for evidence-based medication and therapeutic information. A librarian with a Master's Degree in Library Science who oversees nursing related content at the University's library teaches one of the lectures. The other lecture is taught by the nurse (CBM) and pharmacist (AM) and discusses additional credible resources for finding drug information, using pre-printed prescriber order protocols in hospital settings, and using evidence in practice. We also incorporate specialized content areas (e.g. immunization, mental health, interprofessional team skills, critical appraisal). A lecture regarding effect sizes of risks and benefits of medications serves to challenge the students to evaluate pharmacotherapeutic information with a critical lens and consider the health literacy (and numeracy) of patients. A component of this class includes case studies that are used to demonstrate how numbers can be interpreted variably or in misleading ways. As an example, numerical risk data for bleeding and benefit data for stroke prevention is used for acetylsalicylic acid (ASA) versus warfarin.

\section{Medication administration calculations}

Accurate dosage calculation is essential when preparing medication for administration to minimize the risk for error and patient harm ${ }^{[6]}$. Nursing education, therefore, must continue to develop and promote effective strategies to enhance student performance related to this critical area of nursing accountability. Research related to the numeracy skills of nurses that encourages creative strategies for maintaining competency in calculations have characterized the literature describing: 1) serious numeracy skills deficits in nurses despite a consensus on these skills being required; 2) nursing program prerequisites that should include basic mathematics or diagnostic testing and remediation for such skills; 3) diminishing calculation skills without ongoing practice; and 4) infrequent need for calculations in practice potentially increasing the risk for error ${ }^{[5,7]}$. Students often have a limited understanding of basic arithmetic ${ }^{[8]}$, which impacts their ability to 
accurately calculate common drug dosages calculations ${ }^{[9]}$. Ashby ${ }^{[10]}$ looked at nurses' ability to calculate dosages and found that $56.4 \%$ could not calculate correctly in $90 \%$ of the problems, suggesting a need for regular review/testing. Failing calculation tests as a part of orientation has also been linked with higher rates of medication errors ${ }^{[11]}$. Brady et al. ${ }^{[3]}$ report on the international literature and cite inadequate mathematical skills and calculations as significant contributors to medication errors by nurses. They also cite misplaced decimals as one of the most commonly occurring sources for error ${ }^{[3]}$. McMullan et al. reported significant deficits in numeracy skills of both practicing nurses and nursing students ${ }^{[12]}$. Although practicing nurses did perform better with calculations, more difficulty was experienced by both groups when calculations were related to drug percentages, drips and infusion rates versus solid and liquid, oral dosage forms ${ }^{[12]}$. Others have also shown that despite nurses making significant arithmetical, conceptual or computational errors, they do not recognize that they have a learning need or deficit related to medication calculations ${ }^{[13]}$. The results of Dilles et al. similarly show incongruent results between nursing students' calculation test results and students' perceived abilities in performing calculations correctly ${ }^{[5]}$.

Adams \& Duffield concluded that repeated drilling and clinical experience enhanced the ability of nursing students to calculate drug dosages correctly ${ }^{[14]}$. However, similar to others' findings, the skill level diminished over time ${ }^{[7,14]}$. Case study practice questions, step-by-step paper and pencil instructions, and global instruction/critical thinking have also been demonstrated to improve scores on dosage calculation tests ${ }^{[14]}$.

Based on the evidence and the work of others in nursing education ${ }^{[15-19]}$ the students are provided with: 1) weekly calculations assignments in a self-directed textbook; 2) calculations paper and pencil quizzes at the beginning of each week's lab; 3) weekly in-class step by step instruction; 4) weekly lab case study and actual medications to calculation and prepare as well as simulate administration; 5) an online diagnostic test to indicate to students whether they are ready to take the calculations test that requires a score of $90 \%$ or greater to pass the test; 6 ) one lab that uses actual medication vials and ampoules to practice reconstitution and related calculations of medications that nurses most frequently have difficulty calculating correctly (the nurse worked with the local hospital pharmacy to identify the top ten meds that nurses make errors in calculations with); and 7) small group or individual tutorials to identify areas of difficulty and concentrated one on one instruction prior to final test. With incorporation of all of these strategies, the calculations test scores have improved to approximately $5 \%$ initial failure rate in a class of approximately 180 students.

\section{Teaching strategies with large class sizes}

Large class size is a reality of the current academic world ${ }^{[20,21]}$. Although it can be challenging and the workload is heavy, it provides an exciting opportunity to consistently influence student safety and standards of practice related to the role of the nurse in patient assessment, medication preparation and administration and monitoring for effects. The evidence in the literature for best practices related to teaching large groups is, not surprisingly, similar to that for teaching small classes. Best teaching practices in an academic setting encourage interaction and communication between teacher and students while in class and away from class; setting high expectations and adhering to them; early feedback as well as prompt feedback related to assignments and test scores ${ }^{[21-25]}$. Other recommended strategies for teaching large groups include: group collaboration projects and interprofessional learning experiences ${ }^{[23]}$; variety of teaching strategies to acknowledge different learning styles of the students; interactive strategies that engage the critical thinking and clinical reasoning skills; use of story-telling and clinical examples to teach in the affective domain and help students engage and value the need to master the material; online access to course materials and the course discussion board; and attention to classroom and course organization and management ${ }^{[22]}$.

Another teaching strategy for our large class size has been to use a generalist approach rather than individual clinical pharmacy specialists. The continuity of the course content is strengthened by having the generalist pharmacist work with students. The role-modeling of respect for the expertise of each member of the pharmacist-nurse team and the simulation of real world problem-solving as a team in the classroom has brought about a confidence for students to more frequently collaborate with and benefit from the expertise of the pharmacist in the clinical area. The team teaching strategy also has 
the benefit of either the nurse or the pharmacist being able to provide needed student support, administer/manage course issues related to the CLSC, and share the workload and accountability.

\section{Online Web Learning technology to extend the students' learning opportunities}

The course includes a password-protected online course-space through the University's Learning Management System. This online space serves as a repository for course-related materials (e.g. course syllabus, handouts for all lectures, progress and student grades) and provides communication and learning forums through discussion boards and email. Course professors also use the email tool to contain student communication in one place and allow for sensitive material to be discussed with individual students or groups. Students are instructed to post any questions related to aspects of the course delivery or content such as technical information (e.g. scheduling) and medication administration or pharmacology content on the discussion board. The use of the discussion board, which is moderated by the course professors, allows for students to post questions at their leisure with the ability of other students to share feedback, provide approaches to clinical problems, share reference citations, or reflect on insights from their own knowledge and experiences. To ensure that students receive timely feedback from email or discussion board postings, students are informed that their communications will be read within 24 hours and responses typically occur within 48 hours or sooner, if possible. Course professors can also use the asynchronous discussion board as a means to enhance and extend clinical examples from the classroom setting or to post related research evidence. As an example, in discussing selective serotonin reuptake inhibitors (SSRIs), citations to observational studies on bleeding risks with SSRIs were posted to demonstrate how adverse effects are often studied in this manner (e.g. case-control and cohort studies) ${ }^{[26,27]}$. Similarly with SSRIs, a citation was used to discuss some of the issues regarding SSRIs and suicide controversies and the methods used to assess causality ${ }^{[28]}$.

For four years of the course, timed, online quizzes were also used as a means of assessing student progress in the course for the pharmacology content. Through verbal feedback and student comments on course ratings, students expressed concern regarding the online quizzes. The issues primarily related to the timed nature of the quizzes vis a vis technology problems and the ability for students to "look-up" answers during the quizzes without learning the material thus leading to poorer preparation towards the cumulative final exam. In response to this feedback, this method of evaluation was changed (see assessments).

\section{Assessments}

\section{Pharmacology content}

The content from pharmacology lectures is assessed throughout the term with seven quizzes that approximate a biweekly distribution. The content on the quiz covers the lecture material since the previous quiz and is not cumulative. Students are able to eliminate their two lowest scores to have their best five quizzes out of $25 \%$ towards their total grade. The pen and paper quizzes have ten multiple-choice questions and students are given ten minutes to complete the quiz at a start of a class. The quiz questions are mixed in level of difficulty and range from picking the correct definition (e.g. pharmacokinetics is defined as....) to clinical application (e.g. determining when a nurse can assume that most of a medication in an overdose has been eliminated by a patient considering the medication half-life, rate of elimination, and serum concentration of the drug). Since the move from online to paper based quizzes, student satisfaction for this assessment style has been positive. Student learning and preparation for the final exam have improved as evidenced by final exam scores and number of successful students passing this component of the course. The final exam accounts for $35 \%$ of the final grade, is cumulative, and has 100 multiple-choice questions testing a range of knowledge including application and rote or factbased principles.

\section{Medication administration and clinical learning and simulation centre (CLSC) content}

Students write a medication administration theory quiz that is 20 multiple choice questions and includes content from the six medication administration lectures and the seven learning experiences from the CLSC. The calculations quiz is 
composed of five different types of calculations questions (i.e. dosage by weight, reconstitution, IV dosage calculation and infusion rate, dosage calculation involving conversion to correct units, choosing the correct syringe and demarking the dose after calculating it) with multiple parts to assess critical thinking. Students must score a $90 \%$ to pass, which is required for successful completion of the course. Students who are unsuccessful after their first attempt have the opportunity to rewrite with remediation required prior to rewriting the test.

Students demonstrate medication administration technique and standards proficiency through simulated case studies. The student is presented with the prescriber's orders, the patient chart, and a mannequin with the medication preparation area similar to that of the local hospital setting. In 30 minutes, an intramuscular and subcutaneous injection are prepared and administered. The CLSC clinical instructor observes and documents the beginning practitioner standards and competencies with respect to communication, assessment skills, patient teaching, laboratory analysis interpretation, administration technique, documentation and monitoring for efficacy and adverse effects. The performance criteria for skills testing for intramuscular, subcutaneous and nasogastric administration can be obtained by contacting the authors.

The course also includes the opportunity for students to develop an interprofessional care plan following an interprofessional educational session that is scheduled as a part of their regular CLSC component. Attendance of the interprofessional learning opportunity with related group work and care plan is worth $10 \%$ of the final grade. Students work together with learners from other professions (e.g. pharmacy, physiotherapy, occupational therapy, social work, speech language pathology) in response to a case study on stroke.

Table 2. Course Evaluation Strategies

\begin{tabular}{|c|c|c|}
\hline $\begin{array}{l}\text { Skills Competence Demonstration } \\
\text { (Clinical Simulation and Learning } \\
\text { Laboratory Component) }\end{array}$ & Pass/Fail & $\begin{array}{l}\text { By Dec. } 5 / 11 \text {, you must successfully demonstrate the skills you have learned in the lab to pass the } \\
\text { course. There will be one opportunity to retest if needed. Lab attendance is required. Testing is } \\
\text { scheduled with your lab instructor for a } 1 / 2 \text { hour period between Nov. } 14 \text { - Dec. } 5 \text {. It is your } \\
\text { responsibility to book a scheduled time with your instructor. Please book EARLY } \odot \text { (by Oct. } 24 \text {, } \\
\text { 2011). }\end{array}$ \\
\hline $\begin{array}{l}\text { Clinical Applications Quiz } \\
\text { (TWO components, A \& B): } \\
\text { • } \\
\text { Theory-Based Quiz } \\
\text { component } \\
\text { • Calculations Quiz } \\
\\
\text { component }\end{array}$ & $\begin{array}{l}10 \% \\
\text { Pass/Fail }\end{array}$ & $\begin{array}{l}\text { Friday, Nov. 4/11, 1030-1200 OR Mon. Nov. } 7 / 11 \text { 1430-1600 in your regular lab location. } \\
\text { A. Twenty multiple choice questions covering medication administration application lecture } \\
\text { content (Lecture \# 1, 2, 5, 8, 11, 15) and lab content (Labs\# 1-7 inclusive). } \\
\text { B. Five calculations questions: You must score } 90 \% \text { or greater on this calculations component of } \\
\text { the quiz to pass this course. Students must show math/calculations. Calculators are allowed to be } \\
\text { used. If a student fails to score } 90 \% \text {, a rewrite will be allowed on Mon. Nov. } 21 / 11 \text { in Room G } 38 \\
\text { Forrest Building after attending a tutorial. Failure to achieve a } 90 \% \text { or }>\text { on the rewritten } \\
\text { calculations component of the quiz means failure of the course. }\end{array}$ \\
\hline Biweekly Quizzes & $25 \%$ & Study material in smaller volumes -Best 5 of 7 quiz marks \\
\hline $\begin{array}{l}\text { Clinical Applications } \\
\text { Assignments: } \\
\qquad \quad \text { Interprofessional Lab } \\
\quad \text { \& Care Plan } \\
\text { • } \quad \text { Lab } 2 \text { \& } 4 \\
\\
\text { Assignments } \\
\text { (10\% each) }\end{array}$ & $10 \%$ & $\begin{array}{l}\text { Must attend, as scheduled in regular lab group, } \\
\text { on Fri. Oct. } 28 \text { or Mon. Oct. } 31-5 \% \\
\text { Development of Interprofessional Care Plan - 5\% } \\
\text { Due: At the start of the next scheduled lab (e.g. if you have Lab } 2 \text { on Monday Sept. } 19 \text { then } \\
\text { assignment is due at the beginning of the next Monday's lab on Sept. } 26 \\
\text { You will work in groups of 3. Collaboration encouraged during assignment preparation. See Lab } \\
\text { Manual for details, ask for clarification on Discussion Board, talk to your lab instructor or make } \\
\text { an appointment to discuss with your course professor } @-)\end{array}$ \\
\hline $\begin{array}{l}\text { Final Exam - } 3 \text { hours } \\
\text { (During Exam Period) }\end{array}$ & $35 \%$ & $\begin{array}{l}\text { Includes content from all lectures EXCEPT Lecture \# 1, 2, 5, 8, 11, 13, 22. No lab content. } 100 \\
\text { multiple choice questions. There will be no supplemental exam as this is considered to be a } \\
\text { clinical course. }\end{array}$ \\
\hline
\end{tabular}

Students are required to do two CLSC assignments in small groups (e.g. three people) and this contributes a maximum of $20 \%$ of the final grade. These assignments require students to consider the information from case studies used in the CLSC and are related to the assessment of a patient and the medication administration technique. This allows for early 
identification of knowledge and psychomotor deficits prior to the final CLSC experience in which they are required to perform comprehensive assessment and administration of medications. The assignments were added based on written student feedback regarding methods of assessment in course evaluations. From 2000 to 2008 students were required to complete a group project that included a case study and a written paper regarding the medications and their assessment of a patient. Due to the large class size and large group numbers, the students received the feedback and group mark near the end of the course rather than receiving timely and iterative feedback on their knowledge base and application skills. The group project and paper were not as reflective of the real world and the nurses' role and the student performance has been enhanced with the addition of the assignment.

\section{Course schedule and strategies}

The course is introduced to the class with a printed outline to explain the expectations, learning assignments and evaluative methods, which are summarized in a table (see Table 2). There is a detailed schedule that numbers the class topics and highlights dates for quizzes, assignments and learning activities to help the students with organization (see Table 3).

Table 3. Detailed Course Schedule

\begin{tabular}{|c|c|c|}
\hline Lecture \# & Date & Topic \\
\hline 1 & 9-Sept F & Introduction Pharmacology \& Nursing \\
\hline 2 & 12-Sept M & General Principles \\
\hline 3 & 14-Sept W & Pharmacokinetics \\
\hline 4 & 16-Sept F & Drug Administration-Oral/Enteral \\
\hline 5 & 19-Sept M & Pharmacodynamics \\
\hline \multicolumn{3}{|c|}{ Sept. 210935 to 0945 Quiz \# 1 ( $1^{\text {st }} 10 \mathrm{~min}$ of class $)$ - Lectures $2,3,5$} \\
\hline 6 & 21-Sept W & Special Populations \\
\hline 7 & 23-Sept F & Dosage Calculation-Oral/Enteral \\
\hline 8 & 26-Sept M & Autonomics I \\
\hline 9 & 28-Sept W & Autonomics II \\
\hline 10 & 30-Sept F & Drug Administration-Parenteral \\
\hline 11 & 3-Oct M & Autonomics III \\
\hline \multicolumn{3}{|c|}{ Oct. 51235 - 1245 Quiz \# 2: (1st 10 min of class) - Lectures 6, 8, 9, 11} \\
\hline 12 & 5-Oct W & Cardiovascular/Renal I \\
\hline 13 & 7-Oct F & Dosage Calculations-Parenteral \\
\hline \multicolumn{3}{|c|}{ Oct. 10 Thanksgiving Holiday - No Class } \\
\hline 14 & 12-Oct W & Cardiovascular/Renal II \\
\hline 15 & 14-Oct F & Preparing Injectable Meds \\
\hline 16 & 17-Oct M & Cardiovascular/Renal III \\
\hline \multicolumn{3}{|c|}{ Oct. 19 Quiz \# 3 1235-1245 ( ${ }^{\text {st }} 10$ min of class) Lectures 12, 14, 16} \\
\hline 17 & 19-Oct W & Anticoagulation/antiplatelet/fibrinolytics \\
\hline 18 & 21-Oct F & Finding Drug Info/Searching for Evidence \\
\hline 19 & 24-Oct M & Infectious disease management I \\
\hline
\end{tabular}


Table 3. (continued)

\begin{tabular}{|c|c|c|}
\hline Lecture \# & Date & Topic \\
\hline 20 & 26-Oct W & Infectious disease management II \\
\hline 21 & 28-Oct F & $\begin{array}{l}\text { Introduction to Interprofessional Learning Lab } \\
\text { Review of Dosage Calculations - Quiz Prep? }\end{array}$ \\
\hline 22 & 31-Oct M & Infectious disease management III \\
\hline \multicolumn{3}{|c|}{ Nov. 2 1235-1245 Quiz \# 4: (1 10 min class): Lectures 17, 18, 19, 20, 22} \\
\hline 23 & 2-Nov W & Infectious disease management IV \\
\hline \multicolumn{3}{|c|}{ Nov. 4 Fri **Theory \& Calculations Quiz**: 1035 - 1205 Location: scheduled lab } \\
\hline 24 & 4-Nov F & Immunization and related concepts \\
\hline \multicolumn{3}{|c|}{ Nov. 7 Mon **Date Theory \& Calculations Quiz**: 1435 - 1605 Location: scheduled lab } \\
\hline 25 & 7-Nov M & Antiemetics/other GI Meds \\
\hline 26 & 9-Nov W & Endocrine I \\
\hline 27 & 14-Nov M & Endocrine II \\
\hline \multicolumn{3}{|c|}{ Nov. 161235 - 1245 Quiz \# 5: ( $\left(^{\text {st }} 10\right.$ min of class) Lectures 23, 24, 25, 26, 27} \\
\hline 28 & 16-Nov W & Endocrine III \\
\hline 29 & 18-Nov F & CNS I \\
\hline 30 & 21-Nov M & CNS II \\
\hline 31 & 23-Nov W & CNS III \\
\hline Nov. $250935-0945$ & Quiz \# 6:(1 10 min of class $)$ & $28,29,30,31$ \\
\hline 32 & 25-Nov F & Communicating medication risks \\
\hline 33 & 28-Nov M & Non-steroidal Antiinflammatories \& Acetaminophen \\
\hline 34 & 30-Nov W & Other analgesics: Opioids, antimigraine \\
\hline \multicolumn{3}{|c|}{ Dec. 2 Quiz \# 7 0935-0945 (In class prior to eval/review): Lectures 32, 33, 34} \\
\hline 35 & 2-Dec F & Study Day - unless snow day earlier in term has pushed timeline back by a day $(;)$ \\
\hline 36 & 5-Dec M & $\begin{array}{l}\text { Quiz \# } 7 \text { ( } 1^{\text {st }} \mathbf{1 0} \text { min of class) } \\
\text { Review for exam }\end{array}$ \\
\hline 37 & 7-Dec W & Student course evaluation \\
\hline
\end{tabular}

\section{Outcomes}

Student and instructor satisfaction with course content and delivery has significantly improved over the last decade and continues. The course consistently receives excellent ratings and comments based on student ratings' of instruction that are used by the University. There is a perceptible difference in the level of student engagement and enthusiasm for the course. Verbal feedback from student in the years following completion of the course demonstrates an appreciation for the effort in coordination and delivery of the course that offers students ample opportunity for learning, practical application, and communication with instructors. Students continue to be successful in the course and this is partly demonstrated by the $100 \%$ pass rates on the calculations quiz.

We routinely receive provincial, regional and national requests for information on course structure regarding content, assignments, and assessment tools. We have also received verbal feedback from clinical instructors regarding the preparedness for students related to pharmacology content and medication administration techniques. Similarly, clinical instructors responsible for supervising students have commented on students' enhanced abilities to be able to exercise 
clinical reasoning and determine a medication-related learning need and find the information they are looking for in credible and appropriate resources.

From an undergraduate program outcome perspective, a school of nursing policy was developed for students to undertake a medication standards and calculations quiz just prior to each clinical experience for the remainder of the program. This policy was developed largely in recognition that the literature evidence indicates routine practice and application of nursing calculation skills is required to maintain competency and alleviate student and faculty concern for errors. This has resulted in fewer students requiring remediation related to dosage calculations in the final year of the program and prior to entering practice.

The successful coordination and delivery of a complex course with large numbers of students and simulated learning experience clinical instructors and faculty requires open communication, collegial relationships, and an ability and willingness to recognize the importance and value of strong foundational knowledge in pharmacology, calculations, and medication administration techniques. Courses of this size and complexity require annual review to identify areas for enhancement or revision in order to maximize the effective and efficient delivery while being responsive to student feedback and suggestions.

\section{References}

[1] Canadian Institute for Health Information. Drug use among seniors on public drug programs in Canada, 2002 to $2008.2010: 60$. Available from: https://secure.cihi.ca/estore/productFamily.htm?locale=en\&pf=PFC1404 (26 July 2012, date last accessed).

[2] Westbrook JI, Duffield C, Li L, Creswick NJ. How much time do nurses have for patients? A longitudinal study quantifying hospital nurses' patterns of task time distribution and interactions with health professionals. BMC Health Serv Res. 2011; 11 : 319. http://dx.doi.org/10.1186/1472-6963-11-319

[3] Brady AM, Malone AM, Fleming S. A literature review of the individual and systems factors that contribute to medication errors in nursing practice. J Nurs Manag. 2009; 17(6): 679-697. http://dx.doi.org/10.1111/j.1365-2834.2009.00995.x

[4] Lawton R, Carruthers S, Gardner P, Wright J, McEachan RR. Identifying the latent failures underpinning medication administration errors: an exploratory study. Health Serv Res. 2012; 47(4): 1437-1459. http://dx.doi.org/10.1111/j.1475-6773.2012.01390.x

[5] Dilles T, Vander Stichele RR, Van Bortel L, Elseviers MM. Nursing students' pharmacological knowledge and calculation skills. Ready for practice? Nurse Educ Today. 2011; 31(5): 499-505. http://dx.doi.org/10.1016/j.nedt.2010.08.009

[6] Doherty C, Mc Donnell C. Tenfold medication errors: 5 years' experience at a university-affiliated pediatric hospital. Pediatrics. 2012; 129(5): 916-924. http://dx.doi.org/10.1542/peds.2011-2526

[7] Cartwright M. Numeracy needs of the beginning registered nurse. Nurse Educ Today. 1996; 16(2): 137-143. http://dx.doi.org/10.1016/S0260-6917(96)80071-2

[8] Gillham DM, Chu S. An analysis of student nurses' medication calculation errors. Contemp Nurse. 1995; 4(2): 61-64. http://dx.doi.org/10.5172/conu.4.2.61

[9] Santamaria N, Norris H, Clayton L, Scott D. Drug calculation competencies of graduate nurses. Collegian. 1997; 4(3): 18-21. http://dx.doi.org/10.1016/S1322-7696(08)60236-X

[10] Ashby DA. Medication calculation skills of the medical-surgical nurse. Medsurg Nurs. 1997; 6(2): 90-94.

[11] Calliari D. The relationship between a calculation test given in nursing orientation and medication errors. J Contin Educ Nurs. 1995; 26(1): 11-14.

[12] McMullan M, Jones R, Lea S. Patient safety: numerical skills and drug calculation abilities of nursing students and registered nurses. J Adv Nurs. 2010; 66(4): 891-899. http://dx.doi.org/10.1111/j.1365-2648.2010.05258.x

[13] Eastwood KJ, Boyle MJ, Williams B, Fairhall R. Numeracy skills of nursing students. Nurse Educ Today. 2011; 31(8): 815-818. http://dx.doi.org/10.1016/j.nedt.2010.12.014

[14] Adams A, Duffield C. The value of drills in developing and maintaining numeracy skills in an undergraduate nursing programme. Nurse Educ Today. 1991; 11(3): 213-219. http://dx.doi.org/10.1016/0260-6917(91)90062-F

[15] Banning M. Pharmacology education: a theoretical framework of applied pharmacology and therapeutics. Nurse Educ Today. 2003; 23(6): 459-466. http://dx.doi.org/10.1016/S0260-6917(03)00064-9 
[16] Banning M. The use of structured assessments, practical skills and performance indicators to assess the ability of pre-registration nursing students' to apply the principles of pharmacology and therapeutics to the medication management needs of patients. Nurse Education in Practice. 2004; 4(2): 100-106. http://dx.doi.org/10.1016/S1471-5953(03)00035-0

[17] Banning M. Approaches to teaching: Current opinions and related research. Nurse Educ Today. 2005; 25(7): 502-508. http://dx.doi.org/10.1016/j.nedt.2005.03.007

[18] Latter S, Rycroft-Malone J, Yerrell P, Shaw D. Nurses' educational preparation for a medication education role: findings from a national survey. Nurse Educ Today. 2001; 21(2): 143-154. http://dx.doi.org/10.1054/nedt.2000.0528

[19] Latter S, Yerrell P, Rycroft-Malone J, Shaw D. Nursing, medication education and the new policy agenda: the evidence base. Int J Nurs Stud. 2000; 37(6): 469-479. http://dx.doi.org/10.1016/S0020-7489(00)00026-2

[20] Leufer T. Student's perceptions of the learning experience in a large class environment. Nurs Educ Perspect. 2007; 28(6):322-326.

[21] Reumann M, Mohr M, Diez A, Dossel O. Assessing learning progress and quality of teaching in large groups of students. Conf Proc IEEE Eng Med Biol Soc. 2008; 2877-2880. 10.1109/IEMBS.2008.4649803.

[22] Blouin RA, Riffee WH, Robinson ET, et al. Roles of innovation in education delivery. Am J Pharm Educ. 2009; 73(8): 154. http://dx.doi.org/10.5688/aj7308154

[23] Forbes H, Duke M, Prosser M. Students' perceptions of learning outcomes from group-based, problem-based teaching and learning activities. Adv Health Sci Educ Theory Pract. 2001; 6(3):205-217. http://dx.doi.org/10.1023/A:1012610824885

[24] Chickering AW, Gamson ZF. Seven Principles for Good Practice in Undergraduate Education. AAHE Bulletin. 1987 ; $39(7)$ : 3-7.

[25] Chickering AW, Gamson ZF. Applying the seven principles for good practice in undergraduate education (New Directions for Teaching and Learning No. 47). San Franscisco, CA: Jossey-Bass; 1991.

[26] de Abajo FJ, Rodriguez LA, Montero D. Association between selective serotonin reuptake inhibitors and upper gastrointestinal bleeding: population based case-control study. BMJ. 1999; 319(7217): 1106-1109. http://dx.doi.org/10.1136/bmj.319.7217.1106

[27] Wessinger S, Kaplan M, Choi L, et al. Increased use of selective serotonin reuptake inhibitors in patients admitted with gastrointestinal haemorrhage: a multicentre retrospective analysis. Aliment Pharmacol Ther. 2006; 23(7): 937-944. http://dx.doi.org/10.1111/j.1365-2036.2006.02859.x

[28] Barbui C, Esposito E, Cipriani A. Selective serotonin reuptake inhibitors and risk of suicide: a systematic review of observational studies. CMAJ. 2009; 180(3): 291-297. http://dx.doi.org/10.1503/cmaj.081514 